\title{
Transmissão de Alternaria spp. através de sementes de feijão e seu efeito sobre a qualidade fisiológica das sementes
}

\author{
Maria Heloisa Duarte de Moraes ${ }^{1}$, José Otávio Machado Menten ${ }^{1}$
}

${ }^{1}$ ESALQ / USP, C.P. 09, Piracicaba, SP, CEP 13418-900, e-mail: mhdmorae@esalq.usp.br e jomenten@esalq.usp.br

Data de chegada: 14/02/2005. Aceito para publicação em: 07/11/2005.

\begin{abstract}
Moraes, M. H. D., Menten, J. O. M. Transmission of Alternaria spp. by common bean seeds and its effects on physiological quality. Summa Phytopathologica, v.32, n.4, p.381-383, 2006.

A great number of pathogens can be transported by seeds; they had capacity to affect physiological quality or to cause diseases in many stages of the culture, reducing yield. One of these pathogens is the causal agent of Alternaria leaf spot. There aren't many researches about seed transmission of distinct Alternaria species and its effects on common bean physiological quality. The present study was carried out with the aim to verify Alternaria species transmission by common bean seeds and the effects on germination and plant emergence in the greenhouse. About $100 \%$ of inoculated

common bean seeds became infected with isolates of A. alternata. Other isolates of Alternaria from distinct species promoted seed infection varying from zero ( 3 - A. cichorii) to $75 \%$ ( 7 - A. carthami). The majority of these isolates was transmitted to seedlings; isolates 1 (Alternaria cichorii) and 4, 5, 8, 9 and 11 (A. carthami) were transmitted in greater percentage. There was no effect on the plant emergence caused by these isolates, and no positive correlation between incidence and infected seedlings was observed. Some isolates of $A$. carthami reduced seed germination.
\end{abstract}

Additional keywords: germination, emergence, Alternaria leaf spot, inoculation.

\section{RESUMO}

Moraes, M. H. D., Menten, J. O. M. Transmissão de Alternaria spp. através de sementes de feijão e seu efeito sobre a qualidade fisiológica das sementes. Summa Phytopathologica, v.32, n.4, p.381-383, 2006.

Sementes de feijão podem transportar grande número de patógenos que têm a capacidade de afetar sua qualidade fisiológica ou causar doenças em diferentes estádios da cultura, afetando seu rendimento. O agente causal da mancha de Alternária do feijoeiro é um desses patógenos, porém não existem muitos estudos avaliando a transmissão de diferentes espécies de Alternaria associadas a essa doença e seu efeito sobre a qualidade fisiológica. Sendo assim, desenvolveu-se este trabalho com o objetivo de verificar a transmissão de espécies de Alternaria através das sementes de feijão e seu efeito sobre a germinação das mesmas e sobre a emergência de plântulas em casa de vegetação. Isolados de Alternaria alternata, A. carthami e A. cichorii foram inoculados em sementes de feijão e estas foram submetidas aos testes de sanidade, germinação e emergência de plântulas em casa de vegetação. A inoculação com os isolados de A. alternata proporcionou sementes com quase $100 \%$ de incidência; os resultados obtidos com os demais isolados variaram de zero, para os isolados 3 (A. cichorii) e 8 e 9 (A. carthami), até $75 \%$ para o isolado 7 (A. carthami). A maioria dos isolados foi transmitida para as plântulas, sendo os isolados 1 (Alternaria cichorii) e 4, 5, 8, 9 e 11 (A. carthami) transmitidos em maior porcentagem. Não se constatou efeito dos isolados sobre a emergência das plântulas e não houve correlação positiva entre a porcentagem de incidência do fungo e a porcentagem de plântulas infectadas. Alguns isolados de A. carthami causaram queda na germinação das sementes.

Palavras-chave adicionais: germinação, emergência, mancha de Alternaria, inoculação.

A mancha de Alternária do feijoeiro é doença considerada de importância secundária, porém tem se mostrado bastante destrutiva em algumas áreas de cultivo intensivo sob pivô (07). Pode ser causada por mais de uma espécie de Alternaria, sendo a semente uma das principais fontes de inóculo da doença. Porém, não existem muitos estudos avaliando a transmissão desse patógenos para a planta e seu efeito sobre as sementes. Portanto, este trabalho foi desenvolvido com o objetivo de estudar a transmissão de isolados de Alternaria spp. das sementes para as plântulas de feijão e avaliar seu efeito sobre a germinação e emergência de plântulas.

Foram obtidos de sementes e folhas de feijão, 7 isolados de Alternaria carthami, 2 de A. cichorii e 2 de A. alternata. Estes foram inoculados em sementes do cultivar Carioca, pelo método do contato (08). Após a inoculação, as sementes foram submetidas ao teste de sanidade, pelo método do papel de filtro (06), ao teste de germinação pelo método do rolo de germinação $(02)$ e ao teste de emergência de plântula em casa de vegetação $(01)$

$\mathrm{O}$ delineamento experimental utilizado foi o inteiramente 
casualizado para os testes de sanidade e germinação, e o de blocos casualizados para casa de vegetação. Utilizaram-se 4 repetições de 100 sementes cada.

Sementes inoculadas com isolados de Alternaria alternata apresentaram, aproximadamente, $100 \%$ de incidência, enquanto que as inoculadas com os outros variaram de zero, para os isolados 3 ( $A$. cichorii) e 8 e 9 (A. carthami). Não houve diferença entre as sementes inoculadas e a testemunha quanto à porcentagem de emergência, porém, constatou-se que todos os isolados foram transmitidos para as plântulas. Alguns em baixa porcentagem (isolados 2, 3, 6, 7 e 10) e outras em porcentagem mais elevada variando de $10 \%$ a $24 \%$, isolados 5 e 11 respectivamente.

Não se observou correlação positiva entre a incidência do fungo nas sementes e a porcentagem de plântulas infectadas, tanto no teste de germinação quanto no de emergência. O mesmo observou Forcelini (03), estudando a transmissão de Bipolaris sorokiniana através de sementes de trigo, que não detectou correlação significativa entre a incidência e taxa de transmissão.

Houve diferença entre os tratamentos quanto à germinação (Tabela 1); os isolados 4, 5, 8 e 11, de $A$. carthami, causaram queda na germinação das sementes. Ito et al. (05) citam Alternaria sp. causando manchas foliares e queda de folhas. Os isolados de Alternaria alternata não afetaram a germinação das sementes, resultado que difere do obtido por Gomes e Dhingra (04), onde sementes de feijão vagem, com alta infecção de Alternaria alternata, não germinaram.

Os dados de plântulas infectadas (P.N.I. + P.A.I.), obtidos no teste do rolo de papel (Tabela 1), confirmam os resultados de casa de vegetação, de que a maioria desses isolados foi transmitida para a

Tabela 1.: Valores médios obtidos através dos testes de sanidade, de germinação e emergência de plântulas em casa de vegetação, com sementes de feijão inoculadas com isolados de Alternaria spp. Piracicaba, 1995.

\begin{tabular}{|c|c|c|c|c|c|c|}
\hline $\begin{array}{c}\text { Isolados de Alternaria } \\
\text { spp. }\end{array}$ & $\begin{array}{c}\text { Incidência } \\
\text { (\%) }\end{array}$ & $\begin{array}{c}\text { Germinação } \\
(\%)\end{array}$ & $\begin{array}{l}\text { P.N.I.* } \\
(\%)\end{array}$ & $\begin{array}{l}\text { P.A.I.* } \\
(\%)\end{array}$ & $\begin{array}{c}\text { Emergência } \\
(\%)\end{array}$ & $\begin{array}{l}\text { P.I.* } \\
(\%)\end{array}$ \\
\hline $1-A$. cichorii & $58^{* * *} \mathrm{~d}$ & $80 \mathrm{abc}$ & $12 \mathrm{a}$ & $7 \mathrm{bc}$ & $90 \mathrm{~ns}$ & $18 \mathrm{a}$ \\
\hline $3-A$. cichorii & $0 \quad \mathrm{~g}$ & $86 \mathrm{a}$ & $1 \mathrm{def}$ & $3 \mathrm{~cd}$ & 91 & $1 \mathrm{de}$ \\
\hline $4-A$. carthami & $35 \mathrm{e}$ & $67 \mathrm{~d}$ & $8 a b c$ & $22 \mathrm{a}$ & 87 & $14 \mathrm{ab}$ \\
\hline $5-A$. carthami & $51 \mathrm{~d}$ & $76 \mathrm{bcd}$ & $5 \mathrm{bc}$ & $14 \mathrm{ab}$ & 89 & $10 \mathrm{abc}$ \\
\hline $7-A$. carthami & $75 \mathrm{c}$ & $85 \mathrm{ab}$ & $3 \mathrm{~cd}$ & $6 \mathrm{bc}$ & 93 & 5 bcd \\
\hline $8-A$. carthami & $\mathrm{g}$ & $76 \mathrm{bcd}$ & $10 \mathrm{ab}$ & $13 \mathrm{ab}$ & 88 & $12 \mathrm{ab}$ \\
\hline $9-A$. carthami & $\mathrm{g}$ & $84 \mathrm{ab}$ & $10 \mathrm{ab}$ & $9 \mathrm{bc}$ & 91 & $19 a$ \\
\hline $10-$ A. carthami & $18 \mathrm{f}$ & $87 \mathrm{a}$ & $3 \mathrm{de}$ & $1 \mathrm{de}$ & 90 & $2 \mathrm{de}$ \\
\hline $11-$ A. carthami & $10 \mathrm{f}$ & $72 \mathrm{~cd}$ & $9 \mathrm{ab}$ & $15 \mathrm{ab}$ & 87 & $24 \mathrm{a}$ \\
\hline $2-A$ alternata & $99 \mathrm{a}$ & $86 \mathrm{a}$ & $0 \mathrm{f}$ & $1 \mathrm{de}$ & 92 & 2 de \\
\hline $6-A$. alternata & $93 \mathrm{~b}$ & $84 \mathrm{ab}$ & $0 \mathrm{f}$ & $3 \mathrm{~cd}$ & 88 & 5 bcd \\
\hline Testemunha $* *$ & $\mathrm{~g}$ & $85 \mathrm{ab}$ & $0 \mathrm{f}$ & $0 \mathrm{e}$ & 90 & 0 \\
\hline $\mathrm{CV}(\%)$ & $9,3 \%$ & 4,4 & 23,8 & 23,0 & 6,4 & $27,5 \%$ \\
\hline DMS 5\% & 7,6 & 7,0 & 6,2 & 8,1 & 11,3 & 10,8 \\
\hline
\end{tabular}

*PNI=plântula normal infectada; PAI=plântula anormal infectada; PI=plântula infectada no teste de emergência

** Testemunha: sementes não inoculadas

*** Médias seguidas pela mesma letra não diferem entre si, ao nível de $5 \%$ de probabilidade, pelo teste de Tukey. 
plântula. Os resultados estão de acordo com aqueles encontrados por Rolim et al. (09), que constataram o efeito negativo de Alternaria sp. na qualidade fisiológica das sementes de feijão e sua transmissibilidade da semente para a plântula.

Os resultados deste trabalho confirmam a transmissão de Alternaria spp. por sementes de feijão e indicam que a principal importância do inóculo em sementes desta espécie consiste na transmissão da doença para áreas de cultivo.

\section{AGRADECIMENTOS}

Os autores agradecem à Fundação de Apoio à Pesquisa do Estado de São Paulo, pelo apoio financeiro.

\section{REFERÊNCIAS BIBLIOGRÁFICAS}

1. Beckert. O.P. O uso da hidratação como parâmetro para estimar o desempenho de sementes de soja. Piracicaba, 2001. 37 p. Tese (Doutorado) - Escola Superior de Agricultura "Luiz de Queiroz", Universidade de São Paulo.

2. Brasil. Ministério de Agricultura. Secretaria Nacional de Defesa Agropecuária. Regras para análise de sementes. Brasília, 1992. 365 p.

3. Forcelini, C.A. Incidência, transmissão e controle de Bipolaris sorokiniana em sementes de trigo. 1992. 114p. Dissertação
(Mestrado em Fitopatologia) - Escola Superior de Agricultura "Luiz de Queiroz", Universidade de São Paulo, Piracicaba.

4. Gomes, J.L.L.; Dhingra, O. D. Alternaria alternata, a serious pathogen of white colored snap bean (Phaseolus vulgaris L.) seeds. Fitopatologia Brasileira, Brasília, v. 8, p.173-7, 1983.

5. Ito, M.F.; Dudienas, C.; Castro, J.L. Nova espécie de Alternaria em feijoeiro. In: Congresso Paulista de Fitopatologia, 12., 1989, Araras. Resumos. Jaguariúna, 1989. p.36.

6. Lucca Filho, O.A. Metodologia dos testes de sanidade de sementes. In: Soave, J.; Wetzel, M.M.V. da S.(Ed.). Patologia de sementes. Campinas: Fundação Cargill, 1987. p. 276-98.

7. Menezes, J.R. Controle integrado de doenças em culturas irrigadas por pivô central. In: Congresso Brasileiro de Fitopatologia, 1995, Ilhéus. Fitopatologia Brasileira, Brasília, v.20, Suplemento, p.2078, 1995.

8. Moraes, M.H.D. Mancha de Alternária do feijoeiro: etiologia, resistência do hospedeiro e transmissão por sementes. Piracicaba, 1996. 97 p. Tese (Doutorado) - Escola Superior de Agricultura "Luiz de Queiroz", Universidade de São Paulo.

9. Rolim, P.R.; Centurion, M.A.P.C.; Menten, J.O.M. Alternaria sp. em feijoeiro (Phaseolus vulgaris L.): incidência na semente, tipos morfológicos, patogenicidade e transmissibilidade de diferentes isolados. Summa Phytopathologica, Jaguariúna, v.16, n.2, p.130-9, 1990. 